\title{
O CESARZOWYCH CESARSTWA ŁACIŃSKIEGO (1204-1261) (1). MARIA HRABINA SZAMPANII
}

\author{
ZDZISŁAW PENTEK
}

\begin{abstract}
On the Empresses of the Latin Empire (1204-1261) (1). Maria the countess of Champagne. This article is the first one in the planned series "On the Empresses of the Latin Empire (1204-1261)". This one is dedicated to Maria, the countess of Champagne, who, having set off on a crusade, reached Akka, and there she learned about the election of her husband, Count Baldwin Flanders to be the first Latin emperor. The text presents her biography and highlights her participation in the crusades of her relatives.
\end{abstract}

STReszCZENIE. Artykuł jest pierwszym z planowanego cyklu Ocesarzowych Cesarstwa Łacińskiego (1204-1261). Ten jest poświęcony Marii hr. Szampani, która wyruszywszy na krucjatę, dotarła do Akki, i tam dowiedziała się o wyborze jej męża Baldwina hr. Flandrii na pierwszego cesarza łacińskiego. W tekście przybliżono jej życiorys i naświetlono udział w krucjatach jej krewnych.

Autor: Zdzisław Pentek, Uniwersytet im. Adama Mickiewicza, Wydział Historyczny, ul. Uniwersytetu Poznańskiego 7, 61-614 Poznań, Polska, zp26@amu.edu.pl, ORCID ID: https://orcid.org/0000-0001-65006559

Słowa kluczowe: Maria z Szampanii, Cesarstwo Łacińskie, wyprawy krzyżowe

Keywords: Maria of Champagne, Latin Empire, crusades

Balcanica Posnaniensia. Acta et studia, XXVII, Poznań 2020, Wydawnictwo Wydziału Historii UAM, pp. 4756, ISBN 978-83-66355-54-5, ISSN 0239-4278. Polish text with summaries in English and Polish.

doi.org/10.14746/bp.2020.27.3

O kobietach w Cesarstwie Łacińskim pisano pobieżnie, a jeśli już, to tylko na marginesach syntez ${ }^{1}$. Jest to przede wszystkim wynikiem szczupłych wiadomości wypływających ze źródeł historycznych. To ubóstwo przekazów jest skutkiem zaniedbań kronikarzy, którzy byli skoncentrowani na ukazywaniu bohaterskich i mniej godziwych poczynań dokonywanych przez brać rycerską. W ogóle o paniach, w kontekście ru-

1 J. Longnon, L'Empire Latin de Constantinople et la Principauté de Morée, Paris 1949; R.L. Wolff, The Latin Empire of Constantinople, 1204-1261, w: A history of the crusades II, ed. Kenneth M. Setton, Philadelphia 1962, s. 187-233; Z. Pentek, Cesarstwo Lacińskie (1204-1261). Kolonialne państwo krzyżowców czy Neobizancjum, Poznań 2004; F. Van Tricht, The Latin Renovatio of Byzantium. The Empire of Constantinople (1204-1228), transl. Peter Longbottom, Leiden-Boston 2011. 
chu krucjatowego i związkach z nim napisano niezbyt wiele. Ale są wyjątki, jak choćby książka Kobieta w czasach wypraw krzyżowych Régine Pernoud (1909-1998)². Fragmenty tej publikacji o płci pięknej czasów IV krucjaty i Cesarstwa Łacińskiego są dalekie - mówiąc delikatnie - od kronikarskich przekazów. A mimo to, praca R. Pernoud stanowi wręcz wyjątek na tle historiografii krucjat. Inny, znaczący mediewista francuski Georges Duby (1919-1996), podzielił się ciekawymi refleksjami dotykającymi aspektów życia kobiet w czasach krucjat. Są to przede wszystkim - Rycerz, kobieta i ksiądz. Matżeństwa w feudalnej Francji oraz Damy XII wieku³. Interesująco przedstawiają się dociekania Małgorzaty Dąbrowskiej, która wnikliwie zbadała małżeństwa bizantyńsko-łacińskie w rodzie Paleologów od XIII do XV w. ${ }^{4}$ Praktycznie w każdej z tych publikacji zajmowano się paniami wywodzącymi się z ówczesnych elit bądź aspirującymi do tej wąskiej grupy żon cesarzy lub monarchów. I w tym przypadku jest dość podobnie, gdyż rozważania na temat pań w Cesarstwie Łacińskim, siłą rzeczy mogą dotyczyć tylko elity politycznej, którą interesowali się ówcześni historycy. Wiadomości źródłowe o żeńskiej elicie władzy Cesarstwa Łacińskiego są rozproszone, a informacje o nich dość stereotypowe. Wobec tego, zamierzam podzielić się spostrzeżeniami o władczyniach Cesarstwa Łacińskiego. Należy postawić kilka pytań próbując zrealizować to zamierzenie. Cóż o nich w ogóle wiemy (np. rodzina, pochodzenie, udział przodków w ruchu krucjatowym) oraz w jakich kontekstach dochodziło do ich małżeństw? Jaki był polityczny status żon cesarzy łacińskich i możliwości wpływu na bieżącą politykę?

Zapewne nikt z uczestników IV krucjaty nie spodziewał się w chwili wyruszania z rodzinnych domów we Francji, Flandrii, Szampanii, Lombardii lub Pikardii oraz innych ziem Europy, że kresem (dla większości) wyprawy będzie Konstantynopol, a nie Ziemia Święta. Tym bardziej, nikt z nich nie zakładał, że po niespełna dwóch latach od pobytu w obozie w Wenecji (czerwiec-październik 1202 roku), grupa francuskich i weneckich dygnitarzy będzie wybierała cesarza nowego państwa w maju 1204 roku. A jeśli był cesarz, to nie mógł on być samotnikiem. Cesarz powinien mieć żonę, aby przedłużyć trwanie rodziny, mieć potomków. Słowem, cesarz miał założyć dynastię, to jest oczywiste.

Pierwszą cesarzową łacińską została hrabina Maria z Szampanii, żona Baldwina I (1204-1205), cesarza łacińskiego od 16 maja 1204 r. Tytułowa bohaterka urodziła się w 1174 roku. Była ona córką możnego Henryka I Szczodrego hr. Szampanii

2 R. Pernoud, Kobieta w czasach wypraw krzyżowych, przekł. Iwona Badowska, Gdańsk 1995; zob. s. $146-154$.

3 G. Duby, Rycerz, kobieta i ksiadz. Małżeństwa w feudalnej Francji, przekł. Hanna Geremek, Warszawa 1986 oraz Damy XII wieku, przekł. Alicja i Krzysztof Choińscy, Warszawa 2000 oraz praca zbiorowa Histoire des femmes en Occident sous la direction de Georges Duby et Michelle Perrot, Paris 2000.

4 M. Dąbrowska, Łacinniczki nad Bosforem. Małżeństwa bizantyńsko-łacińskie w cesarskiej rodzinie Paleologów (XIII-XV w.), Łódź 1996. 
(1127-1181) i Marii de France (1145-1198)5, a więc była wnuczką króla Francji Ludwika VII (1137-1180) i Alienor z Akwitanii (ok. 1122-1204). Przodkowie Marii z Szampanii należeli do elity ówczesnego społeczeństwa feudalnej Francji, a do jej krewnych oraz powinowatych należeli królowie Francji oraz Anglii: Filip II August (1186-1226), Ryszard Lwie Serce (1189-1199) i Jan bez Ziemi (1199-1216). Maria miała rodzeństwo: Scholastykę (ok. 1170-1219), Henryka II hr. Szampanii (11661197), o którym będzie mowa poniżej oraz młodszego brata w osobie Tybalda III hr. Szampanii (1179-1201). Dwór w Troyes był również ważnym ośrodkiem na mapie kulturalnej ówczesnej Francji (choćby działalność Chrétiena de Troyes ok. 11351185). Małżeństwo Marii było zaaranżowane z pobudek politycznych, jak to bywało w przypadku tak znakomicie urodzonych panien. Wybór jej przyszłego męża nie był więc sprawą przypadku. O jej zamążpójściu za Baldwina z Hainaut (VII 11711206 ? $)^{6}$, przyszłego dziedzica hrabstwa Flandrii, zdecydowano już 13 maja 1179 roku w Troyes. Tam, jako dzieci poznali się i odbyły się ich zaręczyny. Mieli odpowiednio, pięć i prawie osiem lat ${ }^{7}$.

Baldwin był synem Baldwina V hr. Hainaut (ok. 1150-1195) i Małgorzaty hr. Flandrii (1145-1194). Jego siostrą była Izabella (1170-1190), która w wieku zaledwie dziesięciu lat poślubiła Filipa II Augusta, przyszłego króla Francji. Po niej urodził się Baldwin, a następnie urodziła się Jolanta (1175-1219), o której będzie okazja jeszcze wspomnieć. Młodszym jego rodzeństwem byli także: Filip z Namur zw. Szlachetnym (1175-1212), Henryk (1176-1216), później cesarz łaciński, Sybilla (1179-1217) i Eustachy (zm. 1219).

W niecałe dwa lata od zaręczyn Marii z Baldwinem, zmarł jej ojciec hr. Henryk I. Zgodnie z prawem, narzeczeni musieli osiągnać lata sprawne, a zatem do zawarcia małżeństwa doszło w niecałe siedem lat później. Swego przyszłego męża, Baldwina, Maria poślubiła w Valenciennes 6 stycznia 1186 roku w wieku 12 lat, a pan młody liczył niespełna 14 i pół. Weselu towarzyszyło liczne grono gości: damy, rycerze i niżej urodzeni. Wedle nadwornego kronikarza hrabiów Flandrii, Gisleberta z Mons ${ }^{8}$, mło-

5 Chronica Albrici Monachi Trium Fontium, ed. Ludwig Weiland MGH SS 23, Hannover 1874, s. 876 [dalej Chronica Albrici Monachi Trium Fontium]; Karen S. Nicholas, Countesses as rulers in Flanders, w: Aristocratic women in medieval France, ed. Theodore Evergates, Philadephia 1999, s. 128.

6 Gisleberti Chronicon Hanoniense, ed. Wilhelm Arndt, MGH SS 21, Hannover 1869, s. 519 [dalej Gisleberti Chronicon Hanoniense], o narodzinach Baldwina: Sequente anno Domini 1171, mense Iulio, Marghareta, Balduini uxor, filium peperit Valencenis, Balduinum scilicet, qui post patrem et matrem comitatum Flandrie et comitatum Hanoniensem tenuit.

7 Gisleberti Chronicon Hanoniense, s. 528: o parze narzeczonych: dominica post ascensionem Domini, in Trecis ...et de filia ipsius comitis Henrici Maria et de filio comitis Hanonie Balduino recognovit et iuravit.

8 Gislebert z Mons (ok. 1150-1 IX 1225) był duchownym związanym z dworem w Hainaut, gdzie pełnił różne funkcje jako kapelan, notariusz, kanclerz. Po roku 1200 rozpoczął pracę nad swym dziełem, które w znacznej części jest oparte na autopsji. Wydania poza MGH SS - La chronique de Gislebert de Mons, ed. Léon Vanderkindere, Bruxelles 1904 i thum. na język angielski: Chronicle of Hainaut by 
dzi małżonkowie po weselu zamieszkali w szampańskim zamku Château-Thierry nad Marną. Dziejopis dość skrzętnie scharakteryzował obie postacie:

Iuxta hanc equidem compositionem Balduinus comitis Hanoniensis filius, etatem habens 13 [sic!] annorum, Mariam comitis Campanensis sororem accepit uxorem, etatem 12 annorum habentem, apud Castellum Tyeri. Que quidem Maria obsequiis divinis in orationibus, vigiliis, ieiuniis et elemosinis satis iuvenis cepit intendere: quam vir eius Balduinus, iuvenis eciam miles, caste vivendo, spretis omnibus aliis mulieribus, ipsam/ solam cepit amare amore ferventi, quos in aliquo homine raro invenitur ut soli tantum intendat mulieri et ea sola contentus sit. Nuptiarum quippe sollempne gaudium Valencenis in copia militum et dominarum et cuiuscumque conditionis hominum fuit celebratum ${ }^{9}$.

Małżeństwo wyglądało na szczęśliwie skojarzone, i tak chyba było. Maria, choć pochłonięta modlitwami, czuwaniami, postami oraz jałmużnami, skutecznie oddziaływała na Baldwina, który miał żyć cnotliwie, pogardzając wdziękami innych kobiet i kochał Marię żarliwą miłością - co jak zauważa Gislebert - jest rzadko spotykane u mężczyzny. Być może, zrozumiałe obawy przed podjęciem aktywnego życia w alkowie przez bardzo młodą nastolatkę, pchnęły Marię w świat religijnych rytuałów, o których wspominał Gislebert. Natomiast Baldwin - jak uważa K. Nicholas - nawet narażając się na skrywane drwiny ze strony dworzan, wykazywał niezwykłą cierpliwość i umiar. Tak postępujący mąż Marii nie sprawił, że ich związek małżeński spowodował dla niej traumatyczne skutki.

W listopadzie 1194 roku zmarła Małgorzata, hrabina Flandrii, teściowa Marii, a w grudniu roku następnego jej teść, Baldwin V hr. Hainaut. Po tych bolesnych zdarzeniach, jej małżonek objął dozgonne rządy w hrabstwach Flandrii (1194 jako Baldwin IX) i Hainaut (1195 jako Baldwin VI). W marcu 1195 roku Maria wraz ze swoją prawie rówieśniczką Matyldą hr. Boulogne (1170-1210), zamężną z pierwszym księciem Brabantu, Henrykiem I (1165-1235), wyruszyły w na pielgrzymkę do św. Idziego, ale nie wiadomo, do którego z miejsc jego kultu ${ }^{10}$. W grę wchodzą przede wszystkim główny ośrodek wiązany ze świętym, a więc opactwo Saint-Gilles na południu Francji oraz stosunkowo nieodległe kościoły pod tym wezwaniem tegoż w Liège oraz Brukseli.

Nie wnikając w szczegóły, Maria na arenie politycznej pojawiła się w styczniu 1199 roku pod koniec wojennych zmagań trwających od 1197 roku pomiędzy Filipem Augustem a Ryszardem Lwie Serce ${ }^{11}$. W tym konflikcie jej małżonek opowiadał się za roszczeniami terytorialnymi angielskiego monarchy. Wreszcie 13 stycznia 1199 roku

Gilbert of Mons, transl. Laura Napran, Woodbridge 2005; zob. Thérèse de Hemptinne: Giselbert von Mons, Lexikon des Mittelalters, Bd. 4, München-Zürich 1989, s. 1467-1468.

9 Gisleberti Chronicon Hanoniense, s. 550-551, obszernie o związku małżeńskim Marii z Szampanii oraz Baldwina; Flandria generosa (Continuatio Gislenensis), ed. Ludwig Bethmann, MGH SS 9, Hannover 1861, s. 326 [dalej Flandria generosa].

10 Gisleberti Chronicon Hanoniense, s. 601.

11 J. Bradbury, Filip II August, król Francji 1180-1223, tłum. Idalia Smoczyk-Jackowiak, Oświęcim 2018, s. 124-128. 
w Péronne stanął rozejm między monarchami, do czego miała się przyczynić mediacja Marii z Szampanii. W niecały rok później, 2 stycznia 1200 roku Filip II August podpisał - tym razem z Baldwinem - pokój w tymże Péronne kończąc wzajemne animozje. Baldwin dzięki temu, mógł dodać do swych włości m.in. Aire, Arders, Douai, La Gorgue, Richebourg oraz Saint-Omer ${ }^{12}$.

Natomiast w życiu rodzinnym, małżonkowie Maria i Baldwin, doczekali się potomstwa dopiero około 1199 roku lub w 1200 roku w trzynaście lub czternaście lat po ślubie. Wówczas urodziła się ich pierwsza córka, Joanna Flandryjska (zm. 5 XII 1244), która po śmierci rodziców odziedziczyła ziemie Flandrii oraz Hainaut (12051244).

Niemożna zapominać, że tradycje krucjatowe w rodzinach hrabiów Szampanii oraz Flandrii, zajmowały całkiem okazałe miejsce. Ojciec Marii, hr. Henryk I z Szampanii wziął udział w II krucjacie, również dziadek ze strony matki, król Ludwik VII był krzyżowcem. Starszy brat Marii, Henryk II z Troyes hr. Szampanii był „,seniorem Królestwa Jerozolimskiego", ale nie jego królem. Zginął tragicznie wypadając przez okno pałacu w Akce ${ }^{13}$. Zapewne i Baldwin marzył o udziale w wyprawie krzyżowej. Jego wuj, bezdzietny Filip Alzacki hr. Flandrii (1145-1191) miał również za sobą znaczny bagaż doświadczeń w wyprawach do Outremer. Zrazu przebywał tam od 1177 roku do 1179 roku, a w 1190 roku wyruszył wraz z flandryjskim wojskiem do Palestyny. Jednak III krucjata była ostatnim jego rycerskim epizodem, gdyż padł ofiarą zarazy pod murami obleganej Akki 1 czerwca 1191 roku ${ }^{14}$. Mimo to, Baldwin nie zniechęcił się do zamiarów udziału w wyprawie krzyżowej. Co ciekawe, jego żona również zgłosiła swój udział w planowej przez papieża Innocentego III (11981216) nowej krucjacie przeciwko muzułmanom w Ziemi Świętej. Tak więc, wkrótce po zawarciu pokoju z Filipem Augustem, w Środę Popielcową 23 lutego 1200 roku, Maria i jej małżonek przyjęli krzyż w Brugii w katedrze p. w. św. Donata, czym zadeklarowali chęć udziału w krucjacie ${ }^{15}$. Być może chcąc okazać swą dobroduszność

12 J.C. Moore, Baldwin IX of Flanders, Philip Augustus and the Papal Power, „Speculum” 1962 , t. 37, s. 79-89; J. Bradbury, Filip II August, król Francji 1180-1223, tłum. Idalia Smoczyk-Jackowiak, Oświęcim 2018, s. 70-72. W tym sporze Filipa Augusta z Baldwinem chodziło o posag - hrabstwo Artois który wniosła Izabella z Hainaut, pierwsza żona francuskiego monarchy. Po jej śmierci w 1190 roku, król nie zamierzał zwracać ani hrabstwa ani pieniędzy, tłumacząc się, że są mu niezbędne na uposażenie swego następcy, Ludwika VIII (1223-1226). Koniec końców, Baldwin zgodził się na warunki Filipa Augusta i objął w posiadanie wspomniane ziemie.

13 Ernoul, Chronique d'Ernoul et de Bernard le Trésorier, ed. Louis de Mas-Latrie, Paris 1871, s. 306.

14 Gesta Regis Henrici Secundi et Gesta Regis Ricardi Benedicti abbatis, ed. William Stubbs, vol. 2, London 1867, s. 168, Rolls Series 49; Chronica magistri Rogeri de Houedene, ed. W. Stubbs, vol. 3, London-Cambridge 1870, s. 111, Rolls Series 51.

15 Flandria generosa, s. 326: et anno 1200 cum uxore Maria, sorore Theobaldi Campaniae comitis, Brugis in capite quadragesimae crucem assumpsit; Geoffroy de Villehardouin, La conquête de Constantinople, ed. Edmond Faral..., t. 1-2, Paris 1938-1939 [dalej Villehardouin] § 8: ... se croisa li quens Baudoins de Flandres e de Hainaut, a Bruges, et la contesse Marie sa feme...; J. Bradbury, Filip II 
i zapewnić powodzenie planom wzięcia udziału w wyprawie krzyżowej, Maria wraz z małżonkiem zwolnili z wszelkich powinności opactwa w Ninove i Bohéries. Ale nie wydaje mi się, że to był główny powód takich działań. Podobne dobroczynne kroki podjęła hr. Maria w stosunku do opactwa oo. augustianów w Eekhout na południe od Gandawy. Maria zatwierdziła wraz z małżonkiem prawa mieszczan w Saint-Omer, określając ich mianem „najdroższych przyjaciół” ${ }^{\prime 6}$. Także z Baldwinem w 1198 roku ustanowiła taryfę w stołecznej dla hrabstwa Gandawie, w tzw. Bramie Brabanckiej, z tym jednak, że obowiązek opłat nie dotyczył mieszczan tego miasta ${ }^{17}$. W latach 1200-1202 hrabina była zaangażowana w intensywne przygotowania do wyprawy do Ziemi Świętej łączącej się przecież ze znacznymi wydatkami i przygotowaniami logistycznymi. Jednak w kwietniu 1202 roku Maria nie mogła zrealizować złożonych ślubów krucjatowych. Była po raz kolejny w zaawansowanej ciąży i musiała pozostać w Gandawie ${ }^{18}$. Rozstała się wówczas z mężem, jak się później okazało, na zawsze. On opuścił Flandrię 14 kwietnia 1202 roku i wyruszył na IV krucjatę. Po prawie dwóch miesiącach, 2 czerwca 1202 roku Maria urodziła drugą córkę. Imię Małgorzata (1202-1280), być może otrzymała po swojej babce ojczystej. Małgorzata po śmierci siostry została hrabiną Flandrii (1244-1278) oraz Hainaut (1244-1253 i 1257-1280). W tej nowej sytuacji, po wyjeździe Baldwina, hr. Maria została regentką Flandrii na okres dwóch lat ${ }^{19}$. Hrabina postanowiła, może zgodnie z jakimiś wcześniejszymi ustaleniami z Baldwinem, wyruszyć do Ziemi Świętej, gdzie spodziewała się odnaleźć męża. Jej pozostanie we Flandrii było także podyktowane okresem po urodzeniu dziecka i opieką nad pierworodną córką Joanną ${ }^{20}$. Na czas spodziewanej rozłąki z córkami, aby wyruszyć na wyprawę krzyżową, hr. Maria powierzyła opiekę nad nimi szwagrowi, starszemu bratu męża, Filipowi z Namur zw. Szlachetnym (11751212). Miał on również sprawować władzę w Hainaut ${ }^{21}$.

Odtąd jesteśmy skazani na różne wersje w przekazach źródeł narracyjnych i domysły dotyczące dalszych losów hr. Marii. Według dość podobnie brzmiących relacji, Maria skierowała się do Marsylii, gdzie weszła na pokład statku lub okrętu płynącego do Akki, aby tam dotrzeće 22 . Chronologia wydarzeń nie jest dokładnie zna-

August, król Francji 1180-1223, tłum. Idalia Smoczyk-Jackowiak, Oświęcim 2018, s. 108. Autor twierdzi, że król Francji zachęcał Baldwina do wzięcia udziału w wyprawie.

16 Histoire de la France urbaine II. La ville médiévale, ed. J. Le Goff, Paris 1980, s. 128-129.

17 K.S. Nicholas, op. cit., s. 128. Opactwo w Ninove zostało założone w 1137 roku, działało tam zgromadzenie norbertanów, natomiast konwent w Bohéries należał do cystersów.

18 Villehardouin $\S 317$; zob. p. 22.

19 K.S. Nicholas, op. cit., s. 111-137, 127-130, Maria w czasie trwanie regencji wystawiła dziewięć dokumentów.

20 Villehardouin $\$ 317$.

21 G.M. Spiegel, Romancing the past: the rise of vernacular prose historiography in thirteenth-century France, Berkeley 1993, s. 43.

22 Chronica Albrici Monachi Trium Fontium, s. 884: Flandria generosa, s. 330; Chronicon Hanoniense quod dicitur Balduini Avennensis, ed. Johannes Haller, MGH SS 25, Hannover 1880, s. 448; 
na. Natomiast inne źródło, pochodzące w XIV wieku, Chronica monasterii Sancti Bertini, mówi:

Iohannes de Neele castellanus Brugensis cum trecentis militibus Mariam Flandrie comitissam post maritum suum per occeanum et strictum Marochii usque Massiliam et inde in terram Sanctam ad Ptholomaidam deduxit; ubi expectato marito, quem credebat ibidem adventurum, diu languens, obiit anno Domini $1203^{23}$.

Czy to jest możliwe? Nie sądzę, by przypuszczalnie jesienią 1202 roku Maria wyruszyła na statku lub okręcie przez Atlantyk, Gibraltar i dotarła do Marsylii, ponieważ hrabina ma ,alibi” na pobyt we Flandrii, figurując wówczas w tam wystawianych dokumentach ${ }^{24}$.

Kronikarz wyprawy - szampański marszałek Geoffroy de Villehardouin - zanotował w kontekście Jana z Nêle, że ten obiecał Baldwinowi wypłynięcie z portu macierzystego w 1202 roku, by następnie przez wejście w „cieśniną marokańską" przezimować z okrętami w Marsylii. Obok załóg okrętów na pokładach mieli się znaleźć żołnierze Baldwina i jego brata Henryka oraz szaty, żywność niezbędne na wyprawie do Ziemi Świętej ${ }^{25}$. Jeszcze przed lutym 1203 roku, marszałek Szampanii umieścił wpis, że podczas pobytu krzyżowców w Zadarze dowiedziano się o cumowaniu okrętów Jana z Nêle w Marsylii. Po czym, tę radość zmąciły nowiny. Villehardouin wówczas z rozżaleniem skonstatował, że flota flandryjska - zapewne zgodnie z wcześniejszymi ustaleniami, nic nie wiedząc o zmianie kierunku wyprawy w kierunku Konstantynopola - skierowała się wprost do Palestyny ${ }^{26}$. Późniejsza narracja Villehardouina jest trochę niejasna, ponieważ napisał o Marii, że „...ruszyła w drogę i popłynęła za morze do swego pana; i dotarła do portu w Marsylii ...”. Wynikać z tego mogą trzy wnioski. Pierwszy wniosek jest taki, że Maria popłynęła wprost z jakiegoś portu we Flandrii do Marsylii (chyba tylko w celu uzupełnienia wody i zapasów), a potem dalej do Akki. Drugi wniosek jest taki, że Maria przemieściła się drogą lądową do Marsylii, być może później wsiadła na okręt lub statek i pożeglowała do Akki. Jest i trzeci wniosek, Villehardouin niczego precyzyjnie nie wiedział, lecz po prostu chciał wybrnąć z tej sytuacji. Relacje wszystkich dziejopisów zbiegają się w miejscu wylądowania hr. Marii w Akce, zapewne latem 1204 roku.

\footnotetext{
Villehardouin $\S 317$ : ...le contesse Marie sa dame, qu'il avoit laissie en Flandres ençainte por ce qu'ele no pot avec lui movoir, qui adonc ere cuens, la dame si ajut d'une file...

23 Iohannes Longus de Ipra, Chronica monasterii Sancti Bertini, ed. Oswald Holder-Egger, MGH SS 25, Hannover 1880, s. 824.

${ }^{24}$ K.S. Nicholas, op. cit., s. 128.

25 Villehardouin $\S 48-49:$...En cel termine mut uns estoires de Flandres par mer, u ot mult grant plenté de bone gent armee. De cele estoire si fu chevetaines Johans de Neele, chastellains de Bruges...

26 Villehardouin § 103: ...Ha las! il l'atendirent si malvaisement que onques convenz ne lor tindrent, ainz s'en alerent en Surie, ou il savoient que il ne feroient nul esploit..., Villehardouin zasugerował, że była jakaś nieznana nam umowa, a rejs do Syrii był jej pogwałceniem. Trudno, aby kasztelan z Brugii wiedział po zimowaniu w Marsylii, jak potoczył się rejs hr. Baldwina.
} 
Tam doszły do jej uszu wiadomości o wydarzeniach, które sprawiły, że uczestnicy IV krucjaty prawie w ogóle nie pojawili się w Ziemi Świętej ${ }^{27}$. Również tam, poznała najnowszą wieść z Konstantynopola o elekcji jej męża na pierwszego cesarza łacińskiego oraz o tym, że została cesarzową. Dowodem tego, Baldwin IV ks. Antiochii (ok. 1175-1233) złożył jej hołd ${ }^{28}$. Nie wiadomo dokładnie nic na temat jej nieoczekiwanej śmierci 29 sierpnia 1204 roku w Akce ${ }^{29}$. Wiadomość o śmierci cesarzowej Marii, która nie zdołała nigdy pojawić się w Konstantynopolu przywieźli krzyżowcy, którzy porzucili wyprawę w Wenecji lub Zadarze. Tak wynika z consecutio temporum w dziele Villehardouina. Najpierw wymienia on wodzów rycerskich przybyłych z Ziemi Świętej do Konstantynopola, raczej zwabionych podbojem miasta i pragnących powetować sobie poniesione wydatki na bezowocną militarnie wyprawę do Outremer, a następnie przechodzi do zakomunikowania wiadomości o zgonie cesarzowej Marii ${ }^{30}$. Kronikarz zapewne również niewiele lub nawet nic nie wiedział, co spowodowało śmierć Marii, wszak młodej trzydziestoletniej kobiety. Napisał tylko, że „ogarnęła ją choroba, tak skończyła i umarła” oraz podkreślał, że była „bardzo dobrą damą i bardzo godną" 31 . Wedle tej relacji, cesarz po otrzymaniu tych tragicznych wieści o swej żonie był „wielce smutny”, podobnie, jak baronowie, „ponieważ bar-

27 F. Van Tricht, op. cit., s. 434.

28 Wiadomość o hołdzie relacjonuje Chronica Albrici Monachi Trium Fontium, s. 884; Villehardouin $\S$ 317; Caesar Baronius, Annales ecclesiastici, vol. 20, [Roma] 1864, s. 201, par. 34. Król Leon II z Armenii (1187-1219) w liście do papieża Innocentego III wspomina o niej pod koniec 1204 roku: comitissa Flandriae; F. Van Tricht, op. cit., s. 434-435, o pobycie w Akce i hołdzie Baldwina IV.

29 E. Hautcœur, Documents liturgiques et nécrologiques de l'église collégiale de Saint-Pierre de Lille, Lille-Paris 1895, s. 177, 313, tam w Liber obituum ecclesie beati Petri Insulensis: III Kal. [Aug. 1204] Marie, uxoris B[alduini], imperatoris Constantinopolitani, czyli śmierć Marii przypadałaby na 29 sierpnia 1204 roku, tak zresztą jest w przypisie 6. na tej stronie; Chronique de rimée de Philippe Mouskes, ed. Le Baron de [Frédéric A.F. Th.] Reiffenberg, t. 2, Bruxelles 1838, s. 305, v. 20 375-20 379: Sa feme apriés lui s'en ala,/Ki moult tres-durèment l'ama. A Acre moru de malage,/ Coume Dame lö̈aus et sage;/ Et li quens, ki mout fu senés; Chronica Albrici Monachi Trium Fontium, s. 884: Cum imperator Balduinus comitissam Flandriae mandasset et illa ad eum venisset, facta de eo gravida, ad partes transmarinas abiit, ubi cum esset in Acra princeps Antiochie ad eam venit, et ei vice mariti sui tanquam imperatrici Constantinopolitanae homagium fecit. Quo recepta illa in Acra obiit; w polskim wydaniu kroniki Villehardouina, jednak poszedłem za wskazaniem E. Farala, stąd błędnie 9 VIII 1204, Geoffroy de Villehardouin, Zdobycie Konstantynopola, z języka starofrancuskiego przetłumaczył, wstępem i komentarzami opatrzył Zdzisław Pentek, Poznań 2018, s. 117, przypis 636; Radulphi de Coggeshall Chronicon Anglicanum, ed. J. Stevenson, London 1875, Rolls Series 66, s. 151, rok 1204: Obiit comitissa Flandrensis apud Achon, ex qua comes Baldewinus, postea imperator...; Reineri Annales a. 1066-1230, ed. H. Pertz, MGH SS 16, Hannover 1859, s. 658: Comitissa Flandrensis maritum suum exspectans in Acra moritur peregrina; Sigeberti Gemblacensis Chronica continuationibus, ed. Ludwig Bethmann, MGH SS 6, Hannover 1844, s. 438: 1203 ... Maria uxor predicti Balduini comitis, neptis Philippi illustris regis Francie... tandem Accaron applicuit; Flandria generosa, s. 326: 1200 Uxor vero eius Maria, claris orta natalibus...

30 Villehardouin $\S 315-316,318$.

31 Villehardouin $\S 318$ : ... la dame en proposement de venir a lui: si prost une maladie, sina et mori... mult bone dame et mult honoree. 
dzo życzyli sobie mieć tę damę [jako cesarzową]"32. Inne źródło - Genealogie comitum Flandriae - dodaje: „Uxor vero eius Maria, claris orta natalibus, virum suum insecuta [...] gravibus macerata egritudinibus, ultimum reddidit spiritum"33. Cesarzowa Maria zapewne zmarła wskutek jakiejś zarazy lub nie zniosła trudów podróży lub klimatu Bliskiego Wschodu.

Pierwsza cesarzowa wręcz tragicznie zainaugurowała krótki poczet łacińskich cesarzowych, ale nie było jej dane znaleźć się na koronacji cesarskiej obok Baldwina. Była kobietą odważną, bogobojną, skoro podjęła się trudów uczestnictwa w wyprawie krzyżowej, zdając sobie chyba sprawę, jak wiele ryzykuje wraz z mężem. Nie jest wiadomo, gdzie została pochowana, czy stało się to w Akce, czy w jej pobliżu. O pierwszych cesarskich małżonkach można też napisać w kontekście kresu ich krótkiego życia i jeszcze krótszego panowania, iż okoliczności ich zgonów, miejsca pochówków nie były godne szampańskiej hrabiny i flandryjskiego hrabiego, a tym bardziej, łacińskiej pary cesarskiej. Rola polityczna Marii jako cesarzowej łacińskiej praktycznie nie jest do zbadania, gdyż właściwie nie miała miejsca, stąd wszelkie trudy są skazane na niepowodzenie.

\section{BIBLIOGRAFIA}

A history of the crusades II, ed. by Kenneth M. Setton, Philadelphia 1962.

Bradbury J., Filip II August, król Francji 1180-1223, thum. Idalia Smoczyk-Jackowiak, Oświęcim 2018. Baronius C., Annales ecclesiastici, vol. 20, [Roma] 1864.

Chronica Albrici Monachi Trium Fontium, ed. Ludwig Weiland MGH SS 23, Hannover 1874.

Chronica magistri Rogeri de Houedene, ed. W. Stubbs, vol. 3, London-Cambridge 1870, Rolls Series 51 .

Chronicle of Hainaut by Gilbert of Mons, trans. Laura Napran, Woodbridge 2005.

Chronicon Hanoniense quod dicitur Balduini Avennensis, ed. Johannes Haller, MGH SS 25, Hannover 1880.

Chronique de rimée de Philippe Mouskes, ed. Le Baron de [Frédéric A.F. Th.] Reiffenberg, t. 2, Bruxelles 1838.

Dąbrowska M., Łacinniczki nad Bosforem. Małżeństwa bizantyńsko-łacińskie w cesarskiej rodzinie Paleologów (XIII-XV w.), Łódź 1996.

Duby G., Damy XII wieku, przekł. Alicja i Krzysztof Choińscy, Warszawa 2000.

Duby G., Rycerz, kobieta i ksiadz. Malżeństwa w feudalnej Francji, przekł. Hanna Geremek, Warszawa 1986.

Ernoul, Chronique d'Ernoul et de Bernard le Trésorier, ed. Louis de Mas-Latrie, Paris 1871.

Flandria generosa (Continuatio Gislenensis), ed. Ludwig Bethmann, MGH SS 9, Hannover 1861.

Geoffroy de Villehardouin, La conquête de Constantinople, editée et traduite par Edmond Faral..., t. 1-2, Paris 1938-1939.

32 Villehardouin § 318: ...dont granz diels fu a l'empereor Baudoin et a toz les barons de la terre; car il la desiroient mult avoir a dame.

33 Ioannes de Thielrode, Genealogie comitum Flandriae, ed. L. Bethmann, MGH SS 9, Hannover 1851, s. 330 . 
Geoffroy de Villehardouin, Zdobycie Konstantynopola, z języka starofrancuskiego przetłumaczył, wstępem i komentarzami opatrzył Zdzisław Pentek, Poznań 2018.

Gesta Regis Henrici Secundi et Gesta Regis Ricardi Benedicti abbatis, ed. William Stubbs, vol. 2, London 1867, Rolls Series 49.

Gisleberti Chronicon Hanoniense, ed. Wilhelm Arndt, MGH SS 21, Hannover 1869.

Hautcœur E., Documents liturgiques et nécrologiques de l'église collégiale de Saint-Pierre de Lille, LilleParis 1895, s. 177, 313.

Hemptinne Thérèse de, Giselbert von Mons, Lexikon des Mittelalters, Bd. 4, München-Zürich 1989.

Histoire des femmes en Occident sous la direction de Georges Duby et Michelle Perrot, Paris 2000.

Ioannes de Thielrode, Genealogie comitum Flandriae, ed. L. Bethmann, MGH SS 9, Hannover 1851. Iohannes Longus de Ipra, Chronica monasterii Sancti Bertini, ed. Oswald Holder-Egger, MGH SS 25, Hannover 1880.

La chronique de Gislebert de Mons, ed. Léon Vanderkindere, Bruxelles 1904.

Longnon J., L'Empire Latin de Constantinople et la Principauté de Morée, Paris 1949.

Moore J.C., Baldwin IX of Flanders, Philip Augustus and the Papal Power, „Speculum” 1962, vol. 37.

Nicholas Karen S., Countesses as rulers in Flanders, w: Aristocratic women in medieval France, ed. Theodore Evergates, Philadephia 1999.

Pentek Z., Cesarstwo Eacińskie (1204-1261). Kolonialne państwo krzyżowców czy Neobizancjum, Poznań 2004.

Pernoud R., Kobieta w czasach wypraw krzyżowych, przekład Iwona Badowska, Gdańsk 1995.

Radulphi de Coggeshall Chronicon Anglicanum, ed. J. Stevenson, London 1875, Rolls Series 66

Reineri Annales a. 1066-1230, ed. H. Pertz, MGH SS 16, Hannover 1859.

Sigeberti Gemblacensis Chronica continuationibus, ed. Ludwig Bethmann, MGH SS 6, Hannover 1844.

Spiegel G.M., Romancing the past: the rise of vernacular prose historiography in thirteenth-century France, Berkeley 1993.

Van Tricht F., The Latin Renovatio of Byzantium. The Empire of Constantinople (1204-1228), transl. Peter Longbottom, Leiden-Boston 2011.

Wolff R.L., The Latin Empire of Constantinople, 1204-1261, w: A history of the crusades II, ed. by Kenneth M. Setton, Philadelphia 1962, s. 187-233. 